\title{
THE NEW TANDEM-X CHANGE DEM: SPECIFICATIONS AND INTERFEROMETRIC PROCESSING
}

\author{
M. Lachaise, B. Schweisshelm, T. Fritz
}

Remote Sensing technology Institute, German Aerospace Center, Oberpfaffenhoffen, Germany - marie.lachaise@ dlr.de

KEY WORDS: TanDEM-X Mission, Change DEM, terrain changes monitoring, interferometric processing

\begin{abstract}
:
Since 2017, the TanDEM-X mission aims to acquire data globally to generate another (updated) DEM. This new set of acquisitions, which will be complete in 2020, has a clear temporal separation from those used for the TanDEM-X global DEM. It will therefore allow the creation of a temporally independent DEM, the so-called "TanDEM-X Change DEM" enabling the characterization of terrain changes. Since only one global coverage is being acquired, improvements in e.g. the interferometric data processing are necessary. In particular, an edited version of the existing global TanDEM-X DEM is now the "starting point" for the interferometric processing as detailed in this paper.
\end{abstract}

\section{INTRODUCTION}

For the TanDEM-X mission, which began in 2010, two similar satellites fly together to form a large single-pass bistatic SAR interferometer. The main objective of the mission was to generate a DEM of the entire Earth's landmass. The necessary acquisitions took place until 2015 and the global TanDEM-X DEM was completed in 2016. Although it is relatively recent, some data used for its generation is already more than eight years old. Many changes in topography have taken place, making the global TanDEM-X already partially outdated. Consequently, in 2017 it was decided to acquire an additional global coverage as the satellites have sufficient resources for several more years of operation (Buckreuss et al. 2018) to provide a time independent dataset in a well-defined period from September 2017 to mid-2020. Topographic changes will be observable on a global scale by comparing this new DEM with the global TanDEM-X DEM. The name of the resulting product is therefore "TanDEM-X Change DEM".

After a brief overview of the acquisitions concept, this paper summarizes the specifications of the TanDEM-X Change DEM. It then describes the different steps of its interferometric processing, which is our main focus here, and finally presents some first results.

\section{TANDEM-X CHANGE DEM}

\subsection{Acquisitions}

The acquisition scenario has been improved for the Change DEM acquisitions based on the experience and lessons learned from the acquisitions for the global TanDEM-X DEM. The landmass has been separated into dedicated acquisition areas according to dominant land classes, land types and seasonal changes, as shown in Figure 1 (Bachmann et al. 2018). Table 1 summarizes the acquisition constraints for each acquisition region indicated by the same color as in Figure 1.

The acquisition phase will last until the first half of 2020. For now, about $85 \%$ of the data for the Change DEM is acquired.

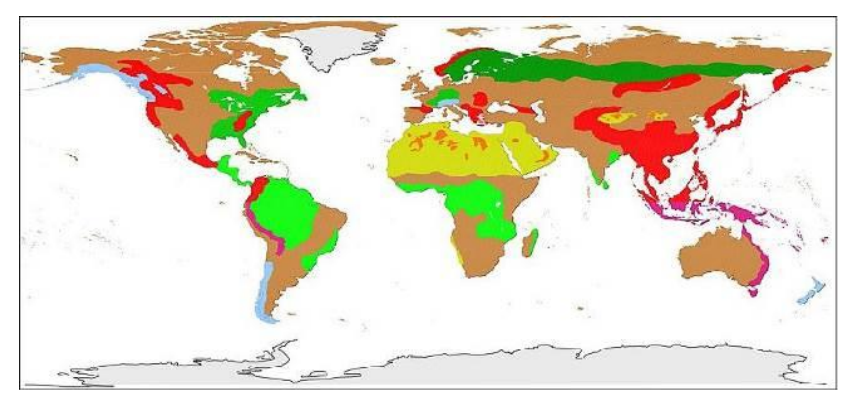

Figure 1. Detected acquisition areas for the TanDEM-X Change DEM acquisition phase (from 2017-09-21 until mid-2020) (Bachmann et al. 2018)

\begin{tabular}{|c|c|c|c|c|c|}
\hline Region & $\begin{array}{l}\text { Cov } \\
\text { era } \\
\text { ges } \\
\end{array}$ & Season & $\begin{array}{l}\text { Height of } \\
\text { Ambiguity }\end{array}$ & $\begin{array}{c}\text { Incidence } \\
\text { Angle } \\
\text { Range }\end{array}$ & $\begin{array}{c}\text { Expected } \\
\text { Relative } \\
\text { Height Error } \\
\end{array}$ \\
\hline $\begin{array}{l}\text { Mountains } \\
\text { with } \\
\text { forest }\end{array}$ & 2 & $\begin{array}{l}\text { Local } \\
\text { ummer }\end{array}$ & $\begin{array}{l}55 m-75 m(15 t) \\
45 m-53 m\left(2^{n d}\right)\end{array}$ & $27-49$ deg & $2 m-4 m$ \\
\hline Glaciers & 2 & $\begin{array}{l}\text { Local } \\
\text { winter }\end{array}$ & $\begin{array}{l}55 m-75 m\left(1^{\text {st }}\right) \\
45 m-53 m\left(2^{\text {nd }}\right)\end{array}$ & $29-47$ deg & $2 m-3 m$ \\
\hline $\begin{array}{l}\text { Tropical } \\
\text { forest }\end{array}$ & 1 & $\begin{array}{l}\text { Year } \\
\text { round }\end{array}$ & $\mathrm{m}$ & $27-49$ deg & $.5 \mathrm{~m}$ \\
\hline $\begin{array}{c}\text { Temperate } \\
\text { and boreal } \\
\text { forest }\end{array}$ & 1 & $\begin{array}{l}\text { Local } \\
\text { summer }\end{array}$ & $5 \mathrm{~m}$ & $27-49 \mathrm{deg}$ & $2.5 m-4 m$ \\
\hline $\begin{array}{c}\text { Deserts } \\
\text { with } \\
\text { mountains }\end{array}$ & 2 & $\begin{array}{l}\text { Year } \\
\text { round }\end{array}$ & $\begin{array}{l}55 m-75 m(15 t) \\
45 m-55 m\left(2^{n d}\right)\end{array}$ & $27-49 \mathrm{deg}$ & $3 m-7 m$ \\
\hline Deserts & 1 & $\begin{array}{l}\text { Year } \\
\text { round }\end{array}$ & $23 m-45 m$ & $14-38$ deg & $2.5 m-5 m$ \\
\hline $\begin{array}{c}\text { Rest of the } \\
\text { world }\end{array}$ & 1 & $\begin{array}{l}\text { Year } \\
\text { round }\end{array}$ & $35 m-45 m$ & $27-49 \mathrm{deg}$ & $1 \mathrm{~m}-2.5 \mathrm{~m}$ \\
\hline
\end{tabular}

Table 1. Acquisitions parameters and expected relative height error for the Change DEM acquisitions

\subsection{Specification}

The Change DEM specifications are derived from those of the final global TanDEM-X DEM (DLR EOC, 2016). It also has 0,4 arcsec posting and similar absolute horizontal and vertical accuracies (see Table 2). In particular, the absolute height accuracy, which is one of the main criteria for detecting of temporal height changes, is also expected to be well below 10 meters. 


\begin{tabular}{|c|c|c|c|c|c|}
\hline DEM Product & Posting & $\begin{array}{c}\text { Absolute } \\
\text { Horizontal } \\
\text { Accuracy } \\
\text { CE90 }\end{array}$ & $\begin{array}{c}\text { Absolute } \\
\text { Vertical } \\
\text { Accuracy } \\
\text { LE90 }\end{array}$ & $\begin{array}{c}\text { Relative Vertical } \\
\text { Accuracy } \\
90 \% \text { linear } \\
\text { point-to-point } \\
\text { error }\end{array}$ & Coverage \\
\hline $\begin{array}{c}\text { TanDEM-X DEM } \\
\text { (standard product) }\end{array}$ & $\begin{array}{c}0.4 \mathrm{arcsec} \\
(\sim 12 \mathrm{~m} \circledast \\
\text { equator) }\end{array}$ & $\begin{array}{l}\text { Specified: }<10 \mathrm{~m} \\
\text { Measured: }<2 \mathrm{~m}\end{array}$ & $\begin{array}{c}<10 \mathrm{~m} \\
\text { Measured: }<2 \mathrm{~m}\end{array}$ & $\begin{array}{l}2 \mathrm{~m} \text { (slope } \leq 20 \%) \\
4 \mathrm{~m} \text { (slope }>20 \%)\end{array}$ & Global \\
\hline $\begin{array}{l}\text { TanDEM-X Change } \\
\text { DEM (CDEM) } \\
\text { (2nd temporal DEM) }\end{array}$ & $\begin{array}{l}0.4 \mathrm{arcsec} \\
(\sim 12 \mathrm{~m} \otimes \\
\text { equator) }\end{array}$ & $<10 \mathrm{~m}$ & $\begin{array}{l}\quad<10 \mathrm{~m} \\
\text { expected similar } \\
\text { to DEM }(<2 \mathrm{~m})\end{array}$ & Not specified & $\begin{array}{c}\text { Global } \\
\text { acquisitions } \\
\text { (with local gaps. }\end{array}$ \\
\hline
\end{tabular}

Table 2. TanDEM-X DEM and Change DEM specifications

However, there are the two major differences between these DEM products:

1. Although the acquisitions are global, the final mosaicked TanDEM-X Change DEM may not be global. There will be gaps due to missing acquisitions or to scenes that are not suitable for mosaicking.

2 . The relative height error will be higher because only one global coverage is available. Table 2 gives an overview of the relative height accuracy to be expected for the different acquisition regions.

In addition, local phase unwrapping errors may remain in the final Change DEM since there are no independent coverages to average/combine. Finally, shadow and layover regions in difficult terrain will not always be filled with data from other viewing geometries.

\section{GENERATION OF THE TANDEM-X CHANGE RAW DEMS}

With only one new global coverage, the dual-baseline framework (Lachaise et al. 2018) developed for the mission can no longer be used. Therefore, the main idea to generate the Change Raw DEMs is to adapt the interferometric part of operational processor ITP (Integrated TanDEM-X Processor, Fritz et al. 2011) to exploit the global TanDEM-X DEM. Its high accuracy provides reliable preliminary terrain height information. Its use greatly facilitates phase unwrapping and, at the same time, allows direct calibration of the new scenes. Nevertheless, editing of the global DEM is a necessity because it is an interferometric surface model that includes noise and artifacts from incoherent areas.

\subsection{TanDEM-X DEM editing}

The global TanDEM-X DEM still contains some small gaps and voids. In addition, water bodies are characterized by noise as their height is exclusively derived from interferometric SAR data. For phase unwrapping, all these areas must have valid elevation values. Two algorithms have been developed at DLR in order to edit the TanDEM-X DEM. Both are capable of identifying and flattening water bodies, interpolating void areas and performing edge-preserving smoothing:

- one algorithm is specific for Antarctic and Greenland. It is semi-automatic and focuses particularly on the derivation of the land/ice-shelf water front. It is applied on the 0,4 arcsec posting TanDEM-X DEM (Huber et al. 2015).

- the other, for the rest of the world, derives and uses reference maps to identify water bodies and fill voids. It is applied to the 1 arcsec posting version of the global TanDEM-X DEM (Gonzalez et al. 2020).

\subsection{Interferometric processing}

Change DEM acquisitions are processed with the "delta-phase" approach of the ITP instead of the dual-baseline phase unwrapping algorithm. It was originally developed for the processing of the High-Resolution DEM acquisitions (Lachaise et al. 2016). The phase simulated from the (edited) TanDEM-X DEM is used for a priori co-registration, to determine the remaining absolute phase offset and trends coming from e.g. baseline estimation errors. Last but not least, it is used to ease single-baseline phase unwrapping (Figure 2). It is important to note, that although the process starts with the first global DEM, the new phase (height) values are independent of the old ones.

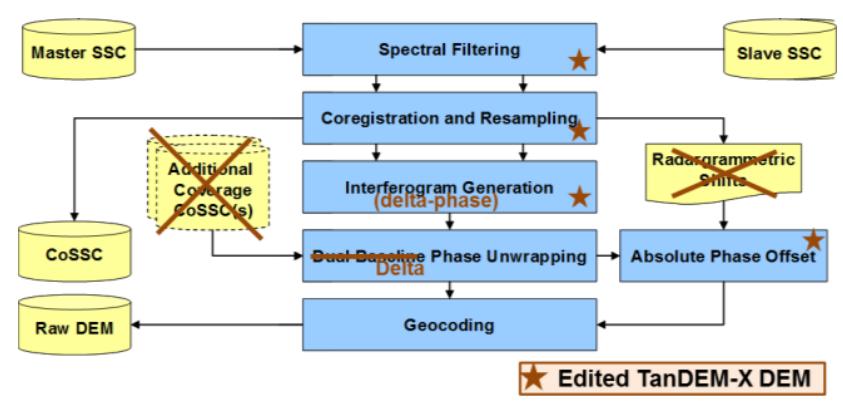

Figure 2. Block diagram of the interferometric part of the operational ITP (SSC stands for Single-look Slant-range Complex image, CoSSC for Coregistered SSC). Updates of the processor are indicated in red. The stars indicate where the TanDEM-X (respectively the phase simulated from it) is used.

3.2.1 The delta-phase: An interferogram $v$ is obtained according to:

$$
v=u_{1} u_{2}^{*}=\left|u_{1}\right|\left|u_{2}\right| e^{j \phi}
$$

where $\phi$ is the interferometric phase $\left(\phi=\phi_{1}-\phi_{2}\right)$. Before the phase unwrapping procedure, the wrapped interferometric phase is usually flattened, i.e. a phase corresponding to a flat Earth (ellipsoid at the mean height of the scene) is removed and only the topographic phase $\phi_{T}$ remains. For the generation of the Change Raw DEMs, the simulated phase from the edited global TanDEM-X DEM is subtracted from the acquired interferometric phase instead of the phase equivalent of a flat Earth. As a consequence, only tiny structures and noise should be visible in this residual phase since the topographic phase is removed. We call this residual phase "delta-phase" (also called differential phase in differential InSAR). Its wrapped version $\delta \varphi_{T}$ is equal to:

$$
\delta \varphi_{T}=W\left\{\phi_{\text {CDEM }}-\phi_{\text {TDM_DEM }}\right\} \in[-\pi ; \pi[
$$

where $W\{$.$\} is the wrapping operator, \phi_{\mathrm{CDEM}}$ is the absolute phase of the Change DEM and $\phi_{\text {TDM_DEM }}$ is the absolute phase simulated from the global TanDEM-X DEM. The unwrapped residual phase $\delta \phi_{T}$ can be written as the sum of the following effects:

$$
\begin{aligned}
\delta \phi_{T}= & \delta \phi_{\neq \text {res }}+\delta \phi_{\text {miscalibration }}+\delta \phi_{\text {noise }}+\delta \phi_{\text {temporal changes }}+ \\
& \delta \phi_{\text {DEM_errors }}+\delta \phi_{\text {PU_error }}
\end{aligned}
$$

where:

- $\delta \phi_{\neq \text {res }}$ represents the phase differences due to the different resolution classes (the interferometric phase has a 0,2 arcsec posting whereas the posting of the edited TDM is 1 arcsec). It contains e.g. finer structures but also differences in slopes in case of abrupt changes in height.

- $\delta \phi_{\text {miscalibration }}$ represents the remaining phase corresponding to an error in the orbits and baseline determination. It is a constant or possibly a trend over the scene. This term must be estimated to provide calibrated Change Raw DEMs. 
- $\delta \phi_{\text {noise }}$ is the sum of the incoherent noise of the new acquisition and the noise of the DEM.

- $\delta \phi_{\text {temporal changes }}$ represents the actual changes in terrain height due to the time interval between the different acquisitions (up to several years). New rainforest clearcuts, lava flow or ice mapped at different seasons for example could be visible in this phase. Ideally, this term should fall within the main band of ambiguity. This is what we want to observe and evaluate.

- $\delta \phi_{\text {DEM_errors }}$ depicts the errors in the TanDEM-X DEM arising from shadow, layover regions and possible small phase unwrapping errors. This term should be close to 0 .

- $\delta \phi_{\mathrm{PU} \_ \text {error }}$ describes possible phase unwrapping errors that occurred during the delta-phase unwrapping. This term must be determined and corrected to allow reliable detection of terrain changes.

Unwrapping the delta-phase is significantly facilitated since only few fringes remain. Nevertheless, large-scale errors in the edited DEM may not be fully recovered by the process despite the moderate HoAs of the new acquisitions, and may affect the performance of the output DEM.

Stable areas, which show no significant change, are also used to pre-calibrate the individual (Raw) DEM scenes prior to geocoding. This further reduces possible offsets and horizontal shifts in the data, and hence, greatly facilitates final calibration and mosaicking. In this way, the so-called pi-ambiguities (i.e. wrongly selected height ambiguity bands due to synchronization phase offsets) are eliminated. The use of the edited DEM reduces the overall processing (no more re-processing due to the pi-ambiguities) and calibration effort in order to mitigate the loss of freedom in selecting appropriate raw DEM data from the available coverages.

3.2.2 Phase unwrapping assessment and error correction: Using the (edited) global TanDEM-X DEM ensures a direct comparison, which should provide the exact location of the phase unwrapping errors (assuming the DEM is correct and not too noisy). The global DEM can even be used directly to correct phase unwrapping errors. Nevertheless, an assessment of the quality of the phase unwrapping quality is necessary. This control must be able to automatically discriminate phase unwrapping errors from the other effects listed in 3.2.1.

For this reason, the assessment consists of different steps:

- a coherence mask is generated and all regions with very low coherence are masked (like forested regions or water);

- a first estimate of the global offset between $\phi_{\mathrm{CDEM}}$ and $\phi_{\text {TDM_DEM }}$ is measured;

- a preliminary discrepancy check is carried out to identify any possible problematic areas that could compromise the offset and trend estimation;

- trends and offset are estimated to calibrate the absolute deltaphase on the global TanDEM-X DEM;

- after calibration, discrepancies are easy to find;

- height discrepancies that are PU errors can be corrected by adding/subtracting an integer number of cycles.

$\delta \phi_{\text {DEM_errors }}$ and $\delta \phi_{\text {temporal changes }}$ might not be clearly distinguishable and depict real inconsistencies between the new acquisitions and the global DEM. $\delta \phi_{\mathrm{PU} \text { _error }}$, on the other hand, represents height differences due to phase unwrapping errors.
Nevertheless, these three components may be difficult to discriminate. The branch-cuts calculated by the Minimum Cost Flow algorithm provide an indicator of phase unwrapping errors since the calibrated residual phase should be smooth and close to 0 . In combination with a phase gradient analysis (steep or smooth gradients), phase unwrapping errors are detectable.

\section{DEMONSTRATION}

For the moment, only a few tiles of the final global TanDEM-X DEM have been edited. As a result, the proposed Change DEM generation process could only be tested on a few different areas, which were selected to represent the different difficulties that can be encountered. In this section, results obtained for the East coast of Devon Island, Canada and Santiago de Chile will be presented.

\subsection{Results over the East coast of Devon Island, Canada}

Devon Island is an island belonging to the Canadian Arctic Archipelago. Several glaciers exist on its east coast. The encountered challenges are: the water surrounding the island may be frozen, snow may have appeared and of course the glaciers have changed. Figure $3 \mathrm{a}$ shows the residual phases ("delta-phases"). The depicted residual phases have few fringes, which dramatically facilitate and fasten phase unwrapping. Nevertheless, there are significant changes in the measured height. Figure $3 b$ presents these changes in blue. The glaciers and the snowy regions exhibit height differences of down to -5 m. By unwrapping the phases independently, the actual heights could be maintained. The red boxes in Figure $3 \mathrm{~b}$ emphasize the overlapping area between the two scenes. The height differences in the two scenes are identical, which proves that the calibration performed in the ITP is correct (at $\mathrm{cm}$ level).

\subsection{Results over Santiago de Chile}

This scene over Santiago de Chile was chosen to study changes over an urban area. It is well known that TanDEM-X DEM is not of good quality over a dense city. Therefore, the changes detected there will not be reliable. In industrial districts however, large buildings or construction sites are clearly visible and can be monitored. Figure 4 shows the calibrated change Raw DEM of the studied scene over the Santiago de Chile region. The acquisition is from 30/04/2018 and has a HoA of 59 $\mathrm{m} /$ cycle. The edited reference DEM is of good quality so that the delta-phase $\delta \phi_{T}$ presented in Equation (4) is dominated by the term $\delta \phi_{\text {temporal changes }}$ representing the changes in height between the new Change DEM acquisition and the reference edited TanDEM-X DEM. Figure 5 shows the height differences observed between the new acquisition and TanDEM-X DEM. In Figure 5a, observed height differences south of the airport are in the orders of $13 \mathrm{~m}$, which is compatible with the height of an industrial building. The construction of these new buildings is confirmed by comparison with the optical images obtained from Google Earth (Google, Maxar technologies). Also on the right hand side, the height differences over a mine are clearly visible. 


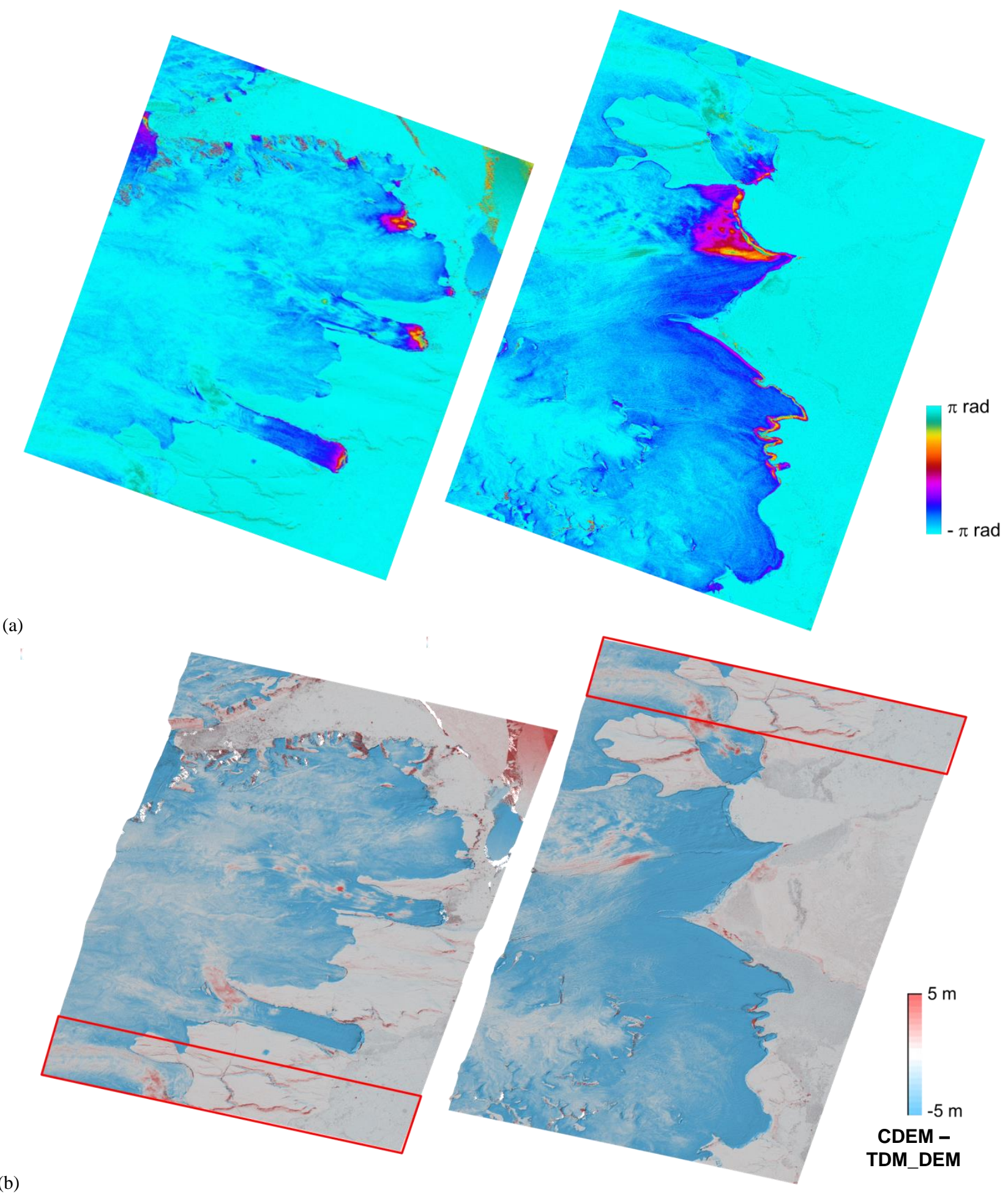

(b)

Figure 3. Two scenes from the same datatake acquired on 02/11/2017 over the east coast of Devon Island (HoA=40 m/cycle). (a) interferometric phases flattened with an edited TanDEM-X DEM; (b) height differences between the new acquisition and the edited reference TanDEM-X DEM. 


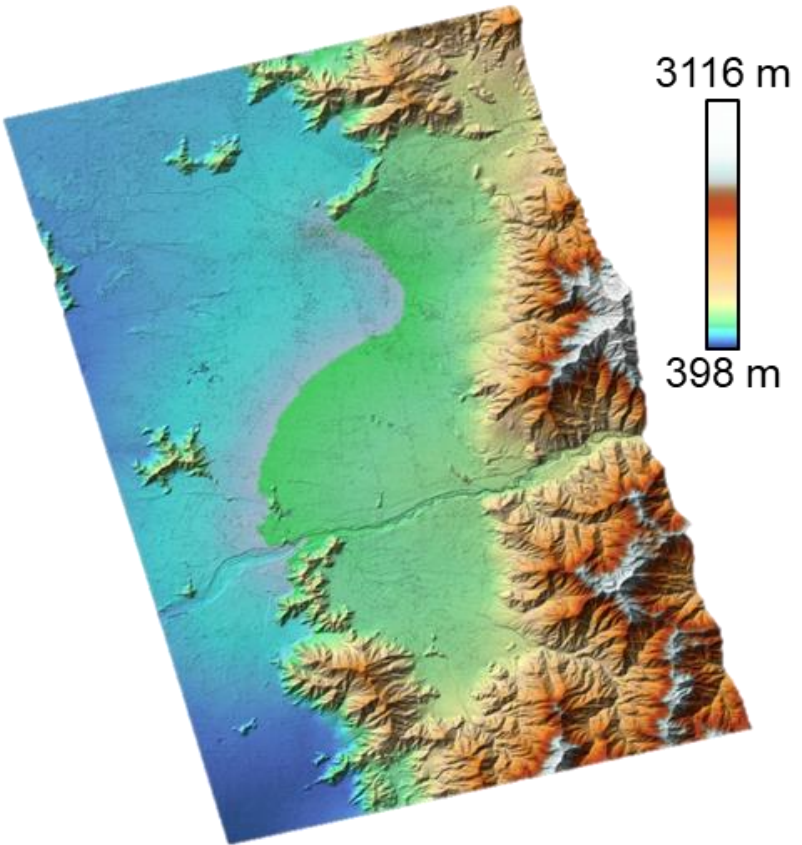

Figure 4. Change Raw DEM of the Santiago de Chile area calibrated to the edited TanDEM-X DEM

\section{CONCLUSION}

This paper aims to show the new developments of the TanDEM-X mission with respect to the Change DEM. It focuses on the interferometric processing of the new acquisitions and the new challenges. This new DEM, generated from new independent global acquisitions, has a sufficient quality and accuracy to enable the retrieval of even small terrain changes on global scales when comparing it to the TanDEM-X global DEM.

\section{REFERENCES}

Bachmann M., Borla Tridon D., Martone M., Sica F., Buckreuss S., Zink M., 2018: How to Update a Global DEM Acquisition Concepts for TanDEM-X and Tandem-L, Proceedings of EUSAR 2018, Aachen, Germany

Buckreuss S., Fritz T., Bachmann M., Zink M., 2018: TerraSAR-X and TanDEM-X Mission Status, Proceedings of EUSAR 2018, Aachen, Germany

DLR EOC, TanDEM-X Ground Segment, 2016: DEM Products Specification Document, Public Document TD-GS-PS-0021, Issue 3.1, https://tandemx-science.dlr.de/

Fritz T., Rossi C., Yague-Martinez N., Rodriguez-Gonzalez F., Lachaise M., Breit H., 2011: Interferometric processing of TanDEM-X data, Proceedings of IGARSS 2011, 2428-2431.

Gonzalez C., Bachmann M., Bueso-Bello J.L, Rizzoli P., Zink M. 2020: Automatic Editing of the TanDEM-X Global DEM, to be presented at EUSAR2020, Leipzig, Germany

Gruber, A., Wessel, B., Huber, M and Roth, A., 2012: Operational TanDEM-X DEM calibration and first validation results. ISPRS J Photogramm Remote Sens, 73, 39-49

Huber M., Wessel B., Wendleder A., Hoffmann J., Roth, A., 2015: A framework for an automated editing of TanDEM-X digital elevation models, Proceedings of IGARSS 2015, 38262829

Lachaise, M., Fritz, T., 2016: Update of the Interferometric Processing Algorithms for the TanDEM-X High Resolution DEMs, Proceedings of EUSAR 2016.

Lachaise M., Fritz T., Bamler R. 2018: The Dual-Baseline Phase Unwrapping Correction Framework for the TanDEM-X Mission Part 1: Theoretical Description and Algorithms, IEEE Transactions on Geoscience and Remote Sensing, 56(2), 780798 
(a)
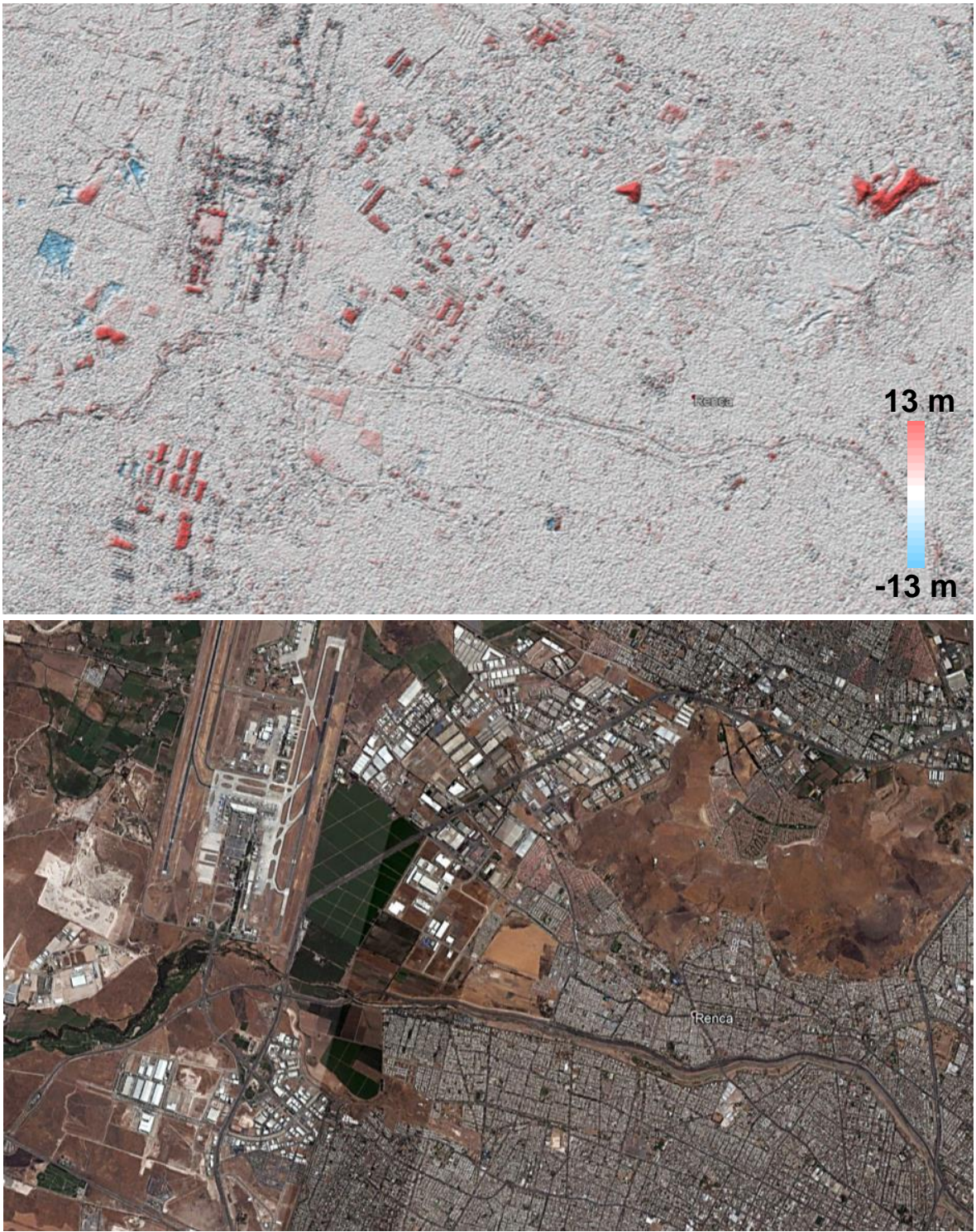

(b)

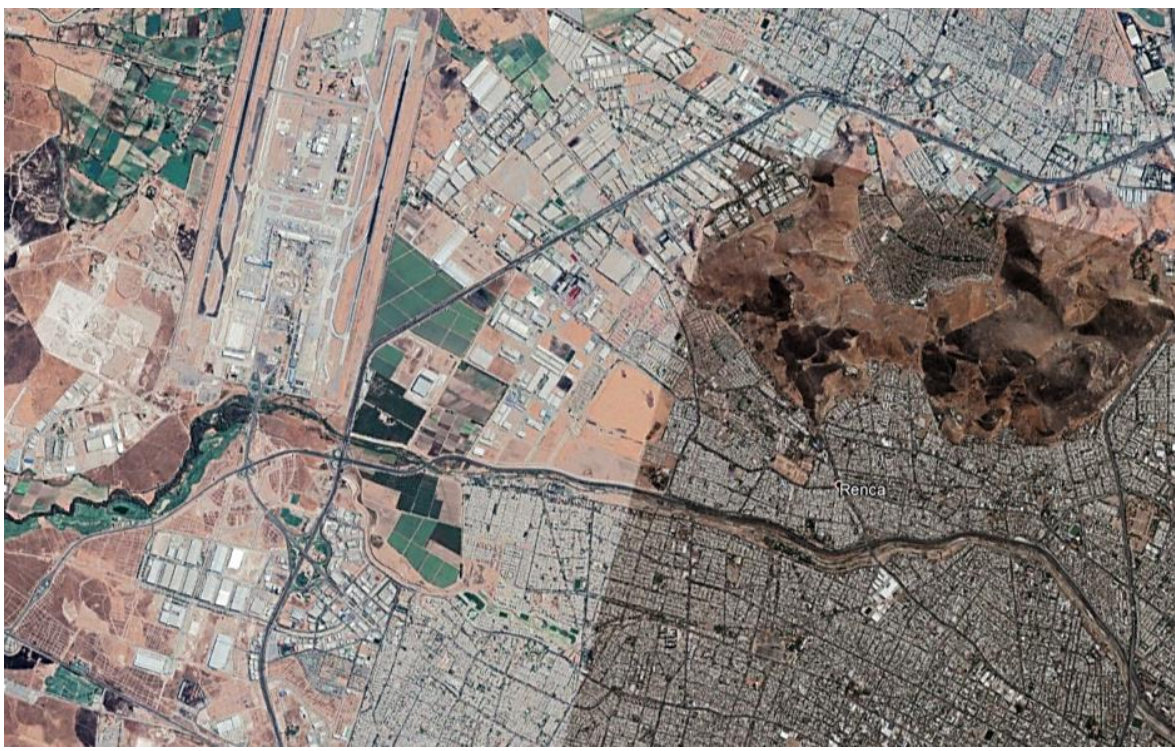

Figure 5. Terrain changes in the industrial area near Santiago de Chile airport: (a) terrain changes map obtained during the interferometric processing of a scene of the Change DEM acquisition (from 30/04/2018); (b) Google Earth photo (Google, Maxar technologies) from 24/02/2015 i.e. taken after the end of the acquisitions for the global TanDEM-X DEM; (c) Google Earth photo (Google, Maxar technologies) from 05/05/2018 i.e. after the Change DEM acquisition. 